(C) 2014 IEEE. Personal use of this material is permitted. Permission from IEEE must be obtained for all other uses, in any current or future media, including reprinting/republishing this material for advertising or promotional purposes, creating new collective works, for resale or redistribution to servers or lists, or reuse of any copyrighted component of this work in other works. 


\title{
A 43-Level 33 kV 3-Phase Modular Multilevel Cascaded Converter for Direct Grid Integration of Renewable Generation Systems
}

\author{
Md. Rabiul Islam, Youguang Guo, Senior Member, IEEE, Mohammad Jafari, Zahra Malekjamshidi, and Jianguo Zhu, \\ Senior Member, IEEE \\ School of Electrical, Mechanical and Mechatronic Systems \\ University of Technology Sydney \\ PO Box 123, Broadway, Sydney, Australia \\ Md.Islam@uts.edu.au and Rabiulbd@hotmail.com
}

\begin{abstract}
This paper proposed a 43-level 3-phase $33 \mathrm{kV}$ modular multilevel cascaded (MMC) converter for direct grid integration of renewable generation systems. A high-frequency magnetic-link is considered to generate isolated and balanced multiple dc sources for all of the H-bridge inverters of the MMC converter. The proposed converter is designed and analyzed taking into account the specified system performance, control complexity, cost and market availability of the semiconductors. The simulation results demonstrate the excellent feature of the proposed medium-voltage converter. It is expected that the proposed new technology will have great potential for future renewable power plants and smart grid applications.
\end{abstract}

Index Terms-Modular multilevel cascaded converter, mediumvoltage, photovoltaic power plants, grid integration.

\section{INTRODUCTION}

Different power electronic converters have been developed using conventional topologies to fulfill the requirements of renewable generation systems [1], [2]. However, it is hard to connect the traditional converters to the grids directly, as the distortion in generated output voltages is high and a single switch cannot stand the grid voltage level. Many power semiconductor vendors such as Semikron, ASEA Brown Boveri (ABB), IXYS, Siemens and Mitsubishi Electric produce devices specially designed for the diode rectifier based converter and back-to-back converter for wind turbine generator systems. All of the devices are in a pack, which reduces the cost and complexity of the power conditioning system. Semikron developed compact modules SKS660FB6U+E1C+B6CI250V06 and IGDD6-4-426-D3816E1F2-BL-FA for the diode rectifier based power conditioning systems. According to the internal circuit configuration, the module SKS660FB6U+E1C+B6CI250V06 is suitable for permanent magnet synchronous generator (PMSG)-based wind turbine generator systems and IGDD6-4-426-D386E1F2-BL-FA is suitable for wound rotor synchronous generator (WRSG)-based wind turbine generator systems. Mitsubishi Electric developed the module CM00MXA-24S with this converter topology which can be used for both the WRSG and PMSG-based wind turbine generator systems. Semikron also developed the module SKSC120GDD69/11A3AWAB1B for power conditioning of synchronous and doubly-fed generator-based wind power systems.

ABB central inverters are especially designed for medium scale photovoltaic (PV) power plants. The PVS800 version is a 3-phase inverter with a power capacity in the range of 100$500 \mathrm{~kW}$. The transformer steps-up the inverter output voltage from $300 \mathrm{~V}$ ac to grid voltage level (e.g., 6-36 kV). Siemens developed the SINVERT PVS inverter for medium scale PV power plants. The ac output voltage and power capacity of the PVS version inverters are in the range of 288-370 V and 500$630 \mathrm{~kW}$, respectively.

With these converters, the conventional renewable generation systems possessing the power-frequency (i.e., 50 or $60 \mathrm{~Hz}$ ) step-up transformer and the line filter and booster not only increase the size, weight and loss but also increase the cost and complexity of the system operation [1]. Today, the industrial trend is to move away from these heavy and large size passive components to power electronic systems that use more and more semiconductor elements controlled by a digital circuit. In such a way, smart operation is ensured. In comparison with conventional two level converters, multilevel converters present lower switching losses, lower voltage stress on switching devices, and better total harmonic 
distortion (THD) [3]-[7]. These remarkable features enable the connection of renewable energy systems directly to the grid without using large, heavy and costly power transformers and also minimize the input and output filter requirements [8]-[14]. Although several multilevel converter topologies have been used in low voltage applications, most of the topologies are not suitable in medium voltage applications. Because of some special features (e.g., the number of components scale linearly with the number of levels and individual modules are identical and completely modular in constriction hence enabling high level attainability), the modular multilevel cascaded (MMC) converter topology can be considered as the best possible candidate for mediumvoltage applications [15], [16]. The high number of levels means that medium-voltage attainability is possible to connect the renewable generation units to the mediumvoltage grid directly and it is also possible to improve the output power quality. The component number and control complexity increase linearly with the increase in the number of levels [1], [17]. Fig. 1 plots the component number and complexity of different level converters.

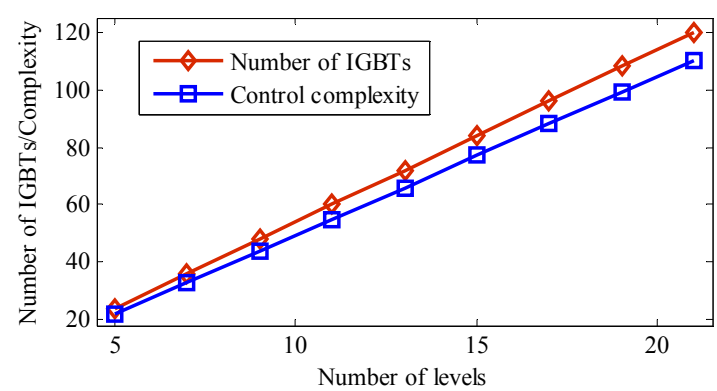

Fig. 1. Number of IGBTs/Control complexity versus converter level numbers of $11 \mathrm{kV}$ system.

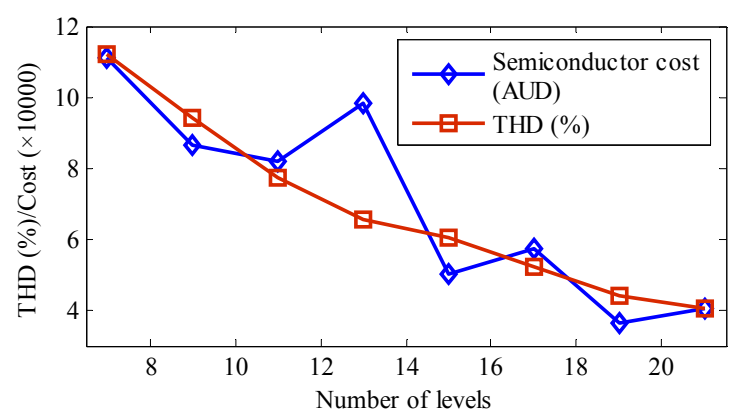

Fig. 2. THD (\%)/Semiconductor cost versus converter level numbers of 11 $\mathrm{kV}$ system.

On the other hand, the distortion in generated output voltage and semiconductor cost of the converter decrease dramatically with the increase of the converter number of levels. Fig. 2 plots THD (\%) and semiconductor cost of different number of MMC converter levels for an $11 \mathrm{kV}$ system. Due to the unavailability of rated insulated gate bipolar transistors (IGBTs), the 13 and 17 level converters used the IGBTs that are used in the 11 and 15 level converters, respectively. Hence, the semiconductor cost curve is up-and-down in nature. Moreover, lower switching frequency, even fundamental switching frequency, can be used with the high level number converter, which significantly reduces the switching losses of the converter. Therefore, the optimal selection in the number of converter levels is important for the best performance/cost ratio of the medium-voltage converter systems and this is one of the central contentions of this paper [17]. In this paper, a $33 \mathrm{kV}$ system is designed and analyzed taking into account the specified system performance, control complexity, and cost and market availability of the power semiconductors. It is found that the 43-level converters are the optimal choice for the $33 \mathrm{kV}$ systems. The design and analysis of a $33 \mathrm{kV}$ MMC converter system is presented in detail in the following sections.

\section{Design of 43-Level 33 KV Modular MultileVel CASCADED CONVERTER}

\section{A. Selection of Number of Level of $33 \mathrm{kV}$ converter}

Each H-bridge inverter cell commutation voltage of a 13level converter is about $4044 \mathrm{~V}$. The highest voltage rating of a commercially available IGBT is $6.5 \mathrm{kV}$, which is recommended for a maximum voltage of $3600 \mathrm{~V}$. Therefore, a 13-level or lower level converter cannot be used to design the $33 \mathrm{kV}$ converter. Each H-bridge inverter cell commutation voltage of a 15-level topology based $33 \mathrm{kV}$ converter is $3467 \mathrm{~V}$ which may be supported by the $6.5 \mathrm{kV}$ IGBT. Owing to this, at least 15-level topology is required to design a $33 \mathrm{kV}$ converter. The output power quality of a 55level inverter is good enough to directly feed into the $33 \mathrm{kV}$ ac grid. The cheap $1.7 \mathrm{kV}$ IGBT can be used to design the 55level inverter. There are no significant performance improvements or cost reductions with converters of more than 55-levels. Moreover, the control complexity increases with the number of converter levels. Due to these, 15-level to 55-level MMC converter topologies are considered for a 33 $\mathrm{kV}$ inverter system.

The arithmetic and logic operations (ALOs) for switching section, THD of output power, and cost of semiconductors are calculated. The number of ALOs is used to compare the complexity of the converters. The THD are calculated through the MATLAB/Simulink environment. Fig. 3 plots the component number and complexity of different level converters for $33 \mathrm{kV}$ system. Fig. 4 plots THD (\%) and semiconductor cost of different number of MMC converter levels for a $33 \mathrm{kV}$ system. Normalized index values are 
calculated. Fig. 5 plots the normalized total index values of different converters. For the $33 \mathrm{kV}$ converter, the total index value is the lowest at the 43-level, because there is no significant output power quality improvement and semiconductor cost reduction for converters with more than 43 levels. In addition, the component number and control complexity increase linearly with the increase in the number of levels. Therefore, 43-level topology is considered as optimal for $33 \mathrm{kV}$ converter systems.

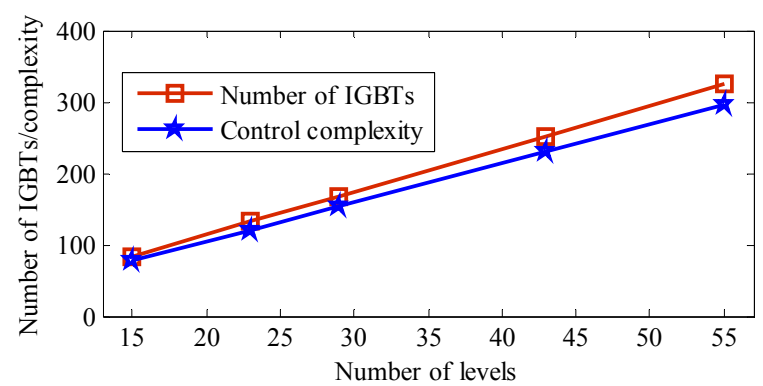

Fig. 3. Number of IGBTs/control complexity versus converter level numbers of $33 \mathrm{kV}$ system.

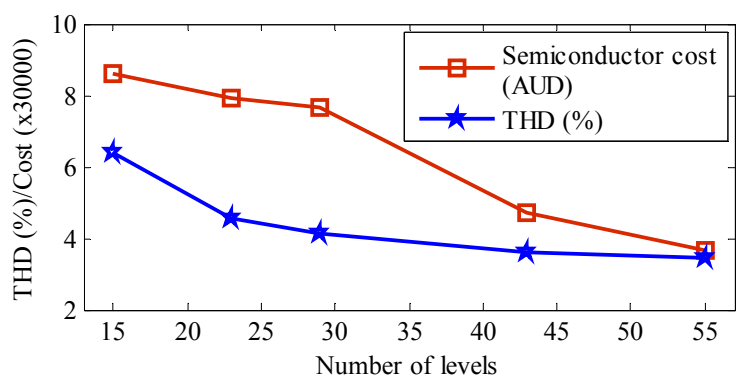

Fig. 4. THD (\%)/Semiconductor cost versus converter level numbers of 33 $\mathrm{kV}$ system.

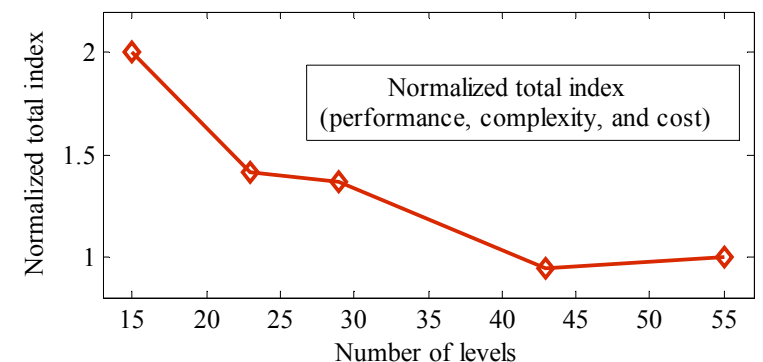

Fig. 5. Normalized total index versus converter level numbers of $33 \mathrm{kV}$ system.

\section{B. Power Circuit of 43-Level 33 kV MMC Converter}

Each H-bridge inverter dc-link voltage rating of a $33 \mathrm{kV}$ 43-level converter is $1156 \mathrm{~V}$. The available cheap and mature $2.5 \mathrm{kV}$ IGBT can be used to design the $33 \mathrm{kV} \mathrm{43-level}$ converter, because this IGBT is recommended for $1200 \mathrm{~V}$ maximum applications. About $96 \%$ device voltage utilization factor (DVUF) can be obtained with the $2.5 \mathrm{kV}$ IGBTs. In total, $21 \mathrm{H}$-bridge inverter cells are on each phase-leg and 252 active switching devices are required for the 3-phase 43-level converter. Fig. 6 shows the circuit diagram of 43-level converter.

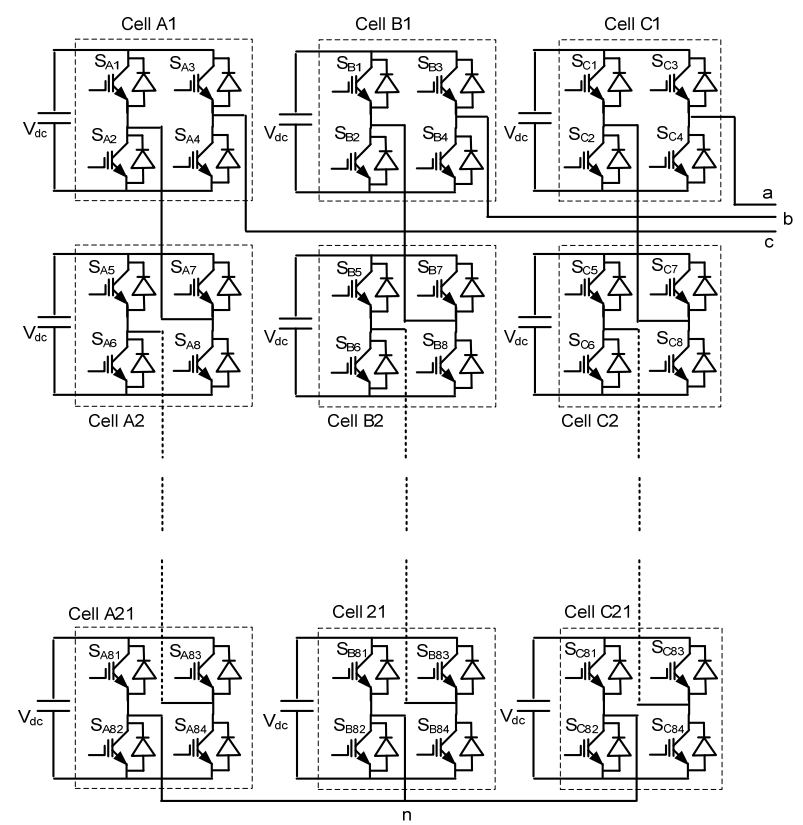

Fig. 6. Circuit diagram of a 43-level MMC converter.

However, the MMC converter requires multiple isolated and balanced dc sources. A high-frequency magnetic-link is considered to generate multiple isolated and balanced $\mathrm{dc}$ supplies for all of the H-bridge inverter cells of the MMC converter from a single or multiple renewable source. The grid electrical isolation and voltage imbalance problems are solved through the common high-frequency magnetic-link [18].

\section{Switching Circuit of 43-Level MMC Converter}

The phase-shifted carriers are specially conceived for FC [19] and MMC [20] converters. Since each FC cell is a twolevel converter, and each H-bridge cell is a 3-level inverter, the traditional bipolar (using one carrier signal that is compared to the reference to decide between two different voltage levels, typically the positive and negative busbars of a voltage source converter) and unipolar pulse width modulation (PWM) techniques can be used, respectively. Due to the modularity of these topologies, each cell can be modulated independently using the same reference signal in a phase. If the peak to peak amplitude of the carriers is $A_{c}$, the amplitude modulation index can be calculated from

$$
m_{a p}=\frac{A_{m}}{A_{c}} .
$$

Fig. 7 shows the basic block diagram of the phase-shifted switching scheme for a 3-phase 43-level converter. If $B_{n}$ is 
the number of the H-bridge inverter cell or pair on a particular phase leg and $m$ the number of converter levels, the carrier phase-shifting for that particular cell or pair can be calculated from

$$
\theta_{p s}=\frac{360^{\circ}\left(B_{n}-1\right)}{(m-1)} .
$$

Each compare unit generates one switching signal for the top switching device of a half-bridge cell or a pair. The inverted form of this switching signal drives the bottom switching device. For the left half-bridge cell, one is asserted when the reference signal value is greater than or equal to the carrier signal value, and the other is asserted when the reference signal value is less than the carrier signal value. For the right half-bridge cell, one is asserted when the inverted carrier signal value is greater than or equal to the reference signal value, and the other is asserted when the inverted carrier signal value is less than the reference signal value. Fig. 8 shows the gate pulse generation technique for the top switching device and the technique to generate gate pulse for the bottom switching device is illustrated in Fig. 9.

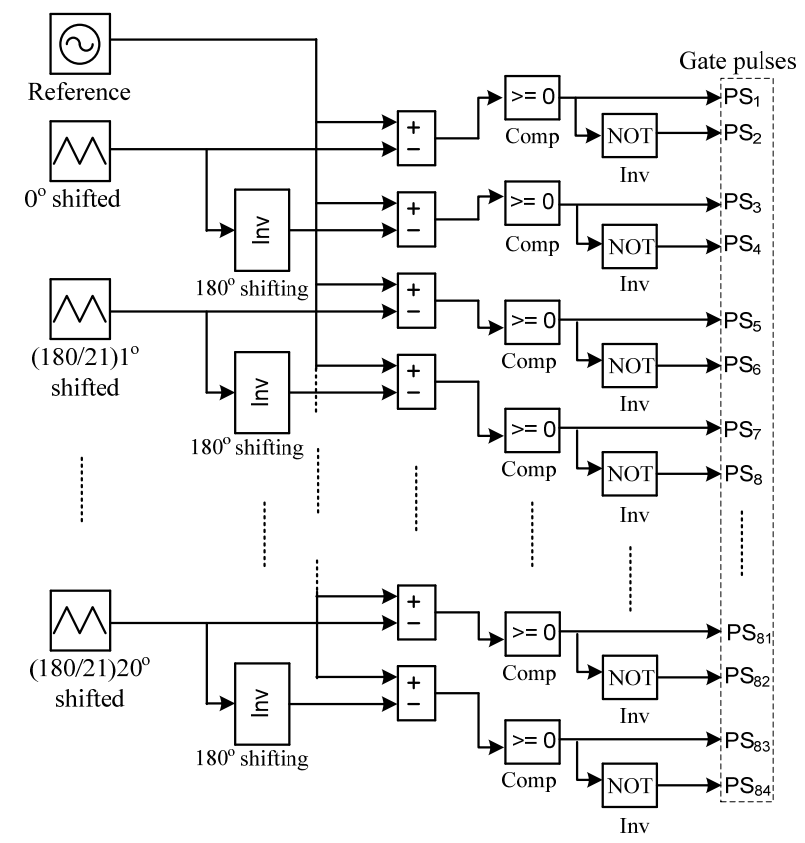

Fig. 7. Switching control scheme of 43-level MMC converter

For the flying capacitor (FC) multilevel converter, the advantage of the even power distribution is that once the flying capacitors are properly charged (initialized to their corresponding values) no imbalance will be produced due to the self balancing property of this topology [21], [22] and as a result there is no need to control the dc-link voltages. Another interesting feature is that the total output voltage has a switching pattern with $\mathrm{k}$ (number of the power cells) times the frequency of the switching pattern of each cell. This multiplicative effect is produced by the phase shifts of the carriers. Hence, better THD is obtained at the output, using the $\mathrm{k}$ time's lower frequency carriers. With the phase-shifted carrier based modulation scheme, the control signal assignment to the appropriate semiconductor of the MMC converter is easy and this remains simple even when the level number increases to higher values.

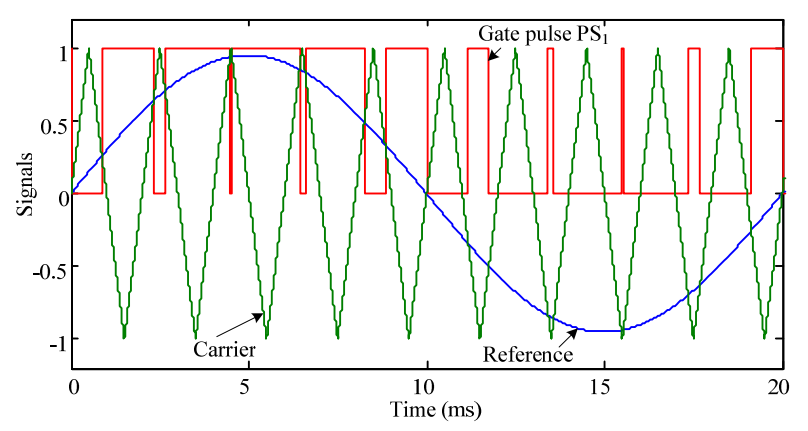

Fig. 8. Generation of gate pulse $\mathrm{PS}_{1}$ with phase shifted carrier.

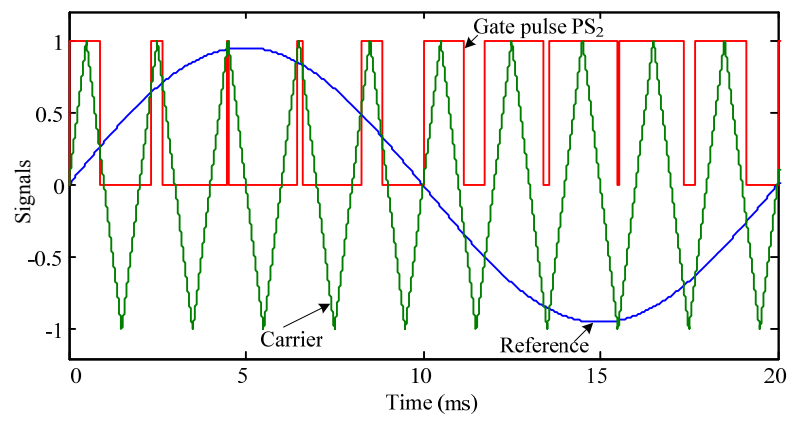

Fig. 9. Generation of gate pulse $\mathrm{PS}_{2}$ with phase shifted carrier.

\section{SimUlation RESUltS}

A total of 231 ALOs are involved with the switching scheme. Although three times more switching devices are used in the 43-level converter, the semiconductor cost is about $41 \%$ lower than that of the 15 -level converter, due to the cheap cost of low voltage rated devices. The line peak to peak voltage consists of 84 voltage levels and each level contributes $1156 \mathrm{~V}$ to the peak to peak line voltage. Due to small step size, the line voltage waveforms are found to be very consistent with the reference sine waveforms. Fig. 10 plots the line voltage waveforms. The output power quality of a 43level converter is good enough to feed into the grid. The line voltage THD is about $3.61 \%$, which satisfies well the 5\% limit by IEEE1547 and IEC61727 standards. The frequency spectrum of line voltage is shown in Fig. 11. Compared with the 15 -level converter, the 43 -level converter provides $44 \%$ better quality output power. As the number of active switching devices has increased three times, the complexity of the 
control scheme of a 43-level converter has also increases three times more than that of a 15 -level converter.

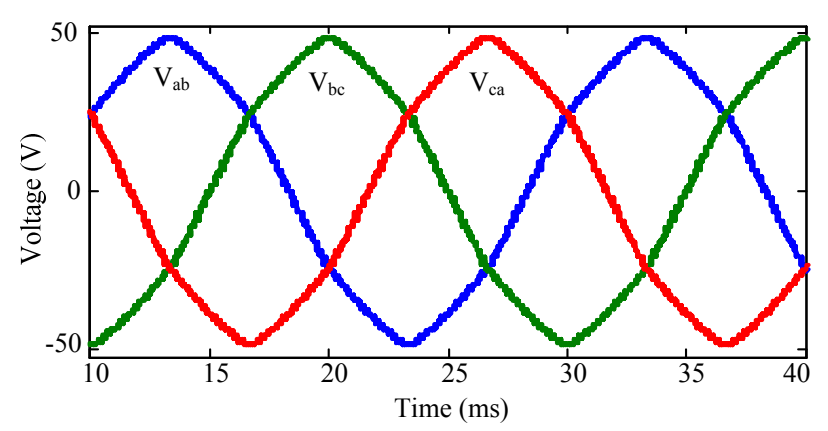

Fig. 10. Line-to-line voltages of 43-level MMC converter.

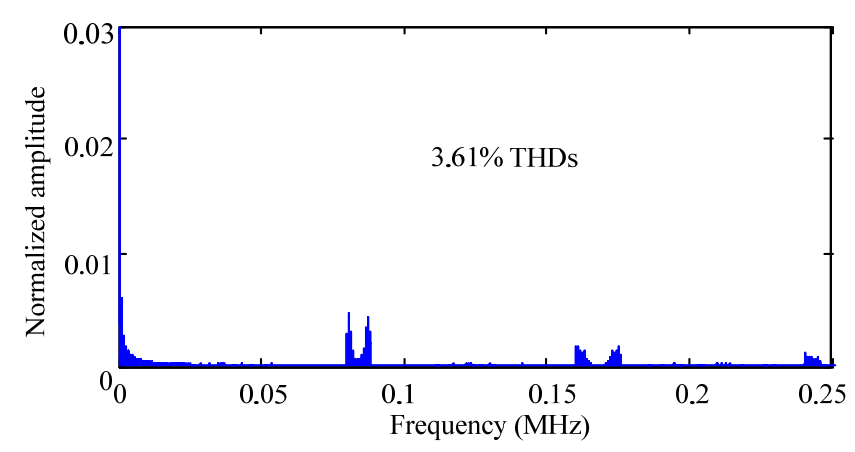

Fig. 11. Line voltage frequency spectrum of 43-level MMC converter.

\section{CONCLUSION}

In this paper, the designs of $33 \mathrm{kV}$ converter systems have been analyzed, which helps in selecting the optimal number of levels for a medium-voltage converter. All possible MMC converter topologies have been considered for the $33 \mathrm{kV}$ converter systems. In order to ensure a cost effective design, the DVUFs were calculated and only the selected converters with high DVUF were considered. During the design process, the availability of the semiconductor devices was considered in the first instance. After checking the availability of devices, the converter systems were designed taking into account three main factors: the specified converter output power quality, complexity of the switching controller, and cost of the semiconductors. The investigation has shown that the 43-level topology is the optimal choice for a $33 \mathrm{kV}$ converter system.

\section{REFERENCES}

[1] M. R. Islam, Y. G. Guo, and J. G. Zhu, "A review of offshore wind turbine nacelle: Technical challenges, and research and developmental trends," Renew. Sustain. Energy Rev., vol. 33, pp. 161-176, May 2014.

[2] M. R. Islam, Y. G. Guo, and J. G. Zhu, "Power converters for wind turbines: Current and future development," In: Materials and Processes for Energy: Communicating Current Research and Technological Developments, pp. 559-571, A. Mendez-Vilas, Ed., Spain, Aug. 2013.

[3] H. Akagi, "Classification, terminology, and application of the modular multilevel cascaded converter (MMCC)," IEEE Trans. Power Electron., vol. 26, no. 11, pp. 3119-3130, Nov. 2011.

[4] B. Gultekin and M. Ermis, "Cascaded multilevel converter-based transmission STATCOM: system design methodology and development of a $12 \mathrm{kV} \pm 12$ MVAr power stage," IEEE Trans. Power Electron., vol. 28, no. 11, pp. 4930-4936, Nov. 2013.

[5] F. Z. Peng, J. S. Lai, J. McKeever and J. VanCoevering, "A multilevel voltage source inverter with separate dc sources for static VAR generation," IEEE Trans. Ind. Appl., vol. 32, no. 5, pp. 1130-1138, Sep./Oct. 1996.

[6] M. Hagiwara, K. Nishmura, and H. Akagi, "A medium-voltage motor drive with a modular multilevel PWM inverter," IEEE Trans. Power Electron., vol. 25, no. 6, pp. 1786-1799, Jul. 2010.

[7] M. Hagiwara and H. Akagi, "Control and experiment of pulse-widthmodulated modular multilevel converters," IEEE Trans. Power Electron., vol. 24, no. 7, pp. 1737-1746, Jul. 2009.

[8] C. H. Ng, M. A. Parker, L. Ran, P. J. Tavner, J. R. Bumby, and E. Spooner, "A multilevel modular converter for a large, light weight wind turbine generator," IEEE Trans. Power Electron., vol. 23, no. 3, pp. 1062-1074, May 2008.

[9] X. Yuan, Y. Li, J. Chai, and M. Ma, "A modular direct-drive permanent magnet wind generator system eliminating the grid-side transformer," in Proc. $13^{\text {th }}$ Eur. Conf. Power Ele. Appl., Barcelona, pp. 1-7, Sep. 2009.

[10] M. R. Islam, Y. G. Guo, and J. G. Zhu, "A medium-frequency transformer with multiple secondary windings for medium-voltage converter based wind turbine generating systems," J. Appl. Phys., vol. 113, no. 17, pp. 17A324-1-17A324-3, May 2013.

[11] X. Yuan, J. Chai, and Y. Li, “A transformer-less high-power converter for large permanent magnet wind generator systems," IEEE Trans. Sus. Energy, vol. 3, no. 3, pp. 318-329, Jul. 2012.

[12] M. R. Islam, Y. G. Guo, and J. G. Zhu, "A high-frequency link multilevel cascaded medium-voltage converter for direct grid integration of renewable energy systems," IEEE Trans. Power Electron., vol. 29, no. 8, pp. 4167-4182, Aug. 2014.

[13] S. Kouro, C. Fuentes, M. Perez and J. Rodriguez, "Single dc-link cascaded H-bridge multilevel multistring photovoltaic energy conversion system with inherent balanced operation," in Proc. the $38^{\text {th }}$ Annual Conf. IEEE Ind. Electron. Society (IECON 2012), Montreal, QC, Canada, 25-28 Oct. 2012, pp. 4998-5005.

[14] H. Choi, W. Zhao, M. Ciobotaru, and V. G. Agelidis, "Large-scale PV system based on the multiphase isolated dc/dc converter," in Proc. the $3^{\text {rd }}$ IEEE Int. Sym. Power Electron. Dist. Gen. Systems, Aalborg, Denmark, 25-28 Jun. 2012, pp. 801-807.

[15] M. R. Islam, Y. G. Guo, and J. G. Zhu, "Performance and cost comparison of NPC, FC and SCHB multilevel converter topologies for high-voltage applications," in Proc. Int. Conf. Elect. Mach. Systems, Beijing, China, 20-23 Aug. 2011, pp. 1-6.

[16] M. R. Islam, Y. G. Guo, and J. G. Zhu, and D. Dorrell, "Design and comparison of $11 \mathrm{kV}$ multilevel voltage source converters for local grid based renewable energy systems," in Proc. the $37^{\text {th }}$ Annual Conf. IEEE Ind. Electron. Society (IECON 2011), Melbourne, Australia, 7-10 Nov., 2011, pp. 3596-3601.

[17] M. R. Islam, Y. G. Guo, and J. G. Zhu, "A multilevel medium-voltage inverter for step-up-transformer-less grid connection of photovoltaic power plants," IEEE J. Photovoltaics, DOI: 10.1109/JPHOTOV. 2014.2310295.

[18] M. R. Islam, Y. G. Guo, Z. W. Lin, and J. G. Zhu, "An amorphous alloy core medium frequency magnetic-link for medium voltage photovoltaic inverters," J. Appl. Phys., vol. 115, no. 17, pp. 17E710-117E710-3, May 2014.

[19] T. A. Meynard and H. Foch, "Electronic device for electrical energy conversion between a voltage source and a current source by means of controllable switching cells," U.S. Patent 5737201 A, Apr. 1998.

[20] P. W. Hammond, "A new approach to enhance power quality for medium voltage AC drives," IEEE Trans. Ind. Appl., vol. 33, no. 1, pp. 202-208, Jan. 1997. 
[21] R. H. Wilkinson, T. A. Meynard, and H. T. Mouton, "Natural balance of multi cell converters: The general case," IEEE Trans. Power Electron., vol. 21, no. 6, pp. 1658-1666, Nov. 2006.

[22] T. A. Meynard, H. Foch, P. Thomas, J. Cournault, R. Jakob, and M. Nahrstaedt, "Multicell converters: Basic concepts and industry applications," IEEE Trans. Ind. Electron., vol. 49, no. 5, pp. 955-964, Oct. 2002. 